Volume 4 no 1

ISSN 2614-2775 (Print)

Tahun 2021

ISSN 2621-8143 (Online)

\title{
PENGARUH LATIHAN INTERVAL JARAK PENDEK TERHADAP DAYA TAHAN JANTUNG PARU PADA SISWA SMA NEGERI 1 GELUMBANG
}

\author{
Hengki Kumbara ${ }^{1}$, Feri Wiratama ${ }^{2}$ \\ Universitas PGRI Palembang ${ }^{1,2}$, Indonesia \\ hengkikumbara88@gmail.com
}

\begin{abstract}
Abstrak
Masalah dalam penelitian ini adalah belum maksimalnya daya tahan jantung paru siswa, hal tersebut berakibat pada buruknya penampilan siswa saat bertanding. Tujuan penelitian ini adalah untuk mengetahui adakah pengaruh latihan interval jarak pendek terhadap daya tahan jantung paru pada siswa SMA Negeri 1 Gelumbang. Dalam penelitian ini metode yang digunakan adalah metode eksperimen dengan jenis one group pretest-postest desain dimana Perlakukan diberikan dengan frekuensi 36 jam latihan yang terbagi dalam 3-4 kali perminggu untuk satuan durasi kerja. Jumlah populasi sebesar 24 orang siswa. Pengumpulan data menggunakan tes bleep/multitahap. Analisis data menggunakan uji t. Adapun hasil penelitian ini dinyatakan bahwa ada pengaruh latihan interval jarak pendek terhadap daya tahan jantung paru pada siswa SMA Negeri 1 Gelumbang karena terdapat peningkatan presentase siswa yang memiliki tingkat $\mathrm{VO}_{2} \mathrm{Max}$ sedang dari $37,5 \%$ menjadi $42 \%$ dan terdapat penurunan jumlah siswa yang memiliki $\mathrm{VO}_{2} \mathrm{Max}$ buruk dari $62,5 \%$ menjadi $58 \%$ setelah diberikan perlakuan latihan interval jarak pendek dan dibuktikan oleh analisis statistik thitung > ttabel yaitu 3,281 >1,717 yang mebuktikan bahwa terdapat pengaruh latihan interval jarak pendek terhadap daya tahan jantung paru sisa SMAN 1 Gelumbang.
\end{abstract}

Kata Kunci. Interval jarak pendek dan daya tahan jantung paru

\section{EFFECT OF SHORT DISTANCE INTERVAL TRAINING ON THE RESISTANCE OF THE LUNG HEART STUDENTS IN SMA NEGERI 1 GELUMBANG}

\begin{abstract}
The problem in this research is that the heart and lung endurance of the students is not yet maximized, this will result in poor students' performance when competing. The purpose of this study was to determine whether there is an effect of short interval training on cardiovascular endurance in students of SMA Negeri 1 Gelumbang. In this study, the method used was an experimental method with the type of one group pretest-postest design where the treatment was given with a frequency of 36 hours of exercise divided into 3-4 times per week for the unit of work duration. The total population is 24 students. Data collection using the bleep / multistage test. Data analysis using t test. The results of this study indicate that there is an effect of short distance interval training on cardiovascular endurance in students of SMA Negeri 1 Gelumbang because there is an increase in the percentage of students who haveVOlevels2moderateMaxfrom $37.5 \%$ to $42 \%$ and there is a decrease in the number of students who have VO2Max is bad from $62.5 \%$ to $58 \%$ after being given short-range interval training treatment and it is proven

Correspondence author: Hengki Kumbara, Universitas PGRI Palembang, Indonesia. E-Mail: hengkikumbara88@gmail.com

(c) (i) (2)

Jurnal HalamanOlahraga Nusantara licensed under a Creative Commons Attribution-ShareAlike 4.0 International License.
\end{abstract}

66 | Halaman Olahraga Nusantara 
by statistical analysis tcount> ttable which is $3.281>1.717$ which proves that there is an effect of short-range interval training on the cardiovascular endurance of the remaining SMAN 1 Gelumbang.

Key Words. Short range intervals and cardiovascular endurance

\section{PENDAHULUAN}

Bermain bola voli saat dalam situasi pertandingan tentu tidak hanya keterampilan teknik yang baik yang dibutuhkan. Pertandingan yang lama dengan rally-rally yang panjang akan sangat menguras energi. Kehabisan energi dalam pertandingan tentu akan berpengaruh besar pada kemampuan teknik seorang pemain. Oleh karena itu setiap pemain bola voli selain harus dibekali dengan kemampuan teknik yang baik, juga harus dibekali dengan kemampuan fisik yang baik pula, mengingat dalam situasi pertandingan kedua jenis kemampuan ini akan saling mendukung antara satu dengan yang lainya.

Salah satu kemampuan fisik yang harus terus ditingkatkan oleh pemain agar saat situasi pertandingan pemain tidak mudah kehabisan energi adalah dengan meningkatkan daya tahan jantung paru (cardiovascular). Daya tahan jantung paru sangat dibutuhkan oleh pemain mengingat perananya adalah menjaga stamina pemain agar terus mampu menjalankan misinya sampai pertandingan berakhir. Daya tahan jantung paru adalah daya tahan yang dimiliki oleh sistem pernfasan dalam rangka kemampuan paru-paru menyuplai oksigen secara terus-menerus saat aktivitas fisik yang berat pada jantung, sehingga jantung mampu mensuplai energi melalui darah pada seluruh permukaan sel dan jaringan. Jika supali oksigen yang diproduksi oleh paru-paru mampu bertahan dengan baik sampai akhir pertandingan, tentu pemain tidak akan gampang mengalami kelelahan, sehingga tidak berakibat buruk pada kemampuan teknik pemain bola voli. Daya tahan paru jantung adalah kemampuan paru-paru jantung mensuplai oksigen untuk kerja otot dalam jangka waktu jadi seseorang yang mempunyai VO2max yang baik maka dalam penggunaan oksigen akan lebih maksimal sehingga daya tahan Kardiorespirasi menjadi lebih baik pula (Kurnia, 2020).

Ada banyak metode yang dapat digunakan oleh pelatih dalam meningkatkan kapasitas volumen oksigen maksimal pemain sehingga pemain mampu memiliki 
daya tahan jantung paru yang baik, misalnya salah satunya adalah interval training. Hal tersebut sesuai dengan pendapat Bayati dalam (Hardiansyah, 2017, hal. 84) bahwa bentuk latihan ini berguna dalam memperbaiki kapasitas fisik melalui penyerapan oksigen maksimal. Latihan ini juga dikatakan sebagai upaya untuk meningkatkan kebugaran jasmani seseorang. Pendapat di atas merupakan gambaran bahwa saat pemain bola voli diberikan menu latihan interval, tentu akan berpengaruh terhadap daya tahan paru jantung pemain. Latihan interval merupakan jenis latihan yang pola gerakannya mirip dengan pola gerakan permainan bola voli. Unsur-unsur gerakan saat bermain bola voli adalah pemain kadang-kala harus mengeluarkan kecepatan yang tiba-tiba, kadang kala berhenti sejenak, lalu bergerak bebas. Sedangkan latihan interval pola gerakannya adalah dengan berlari cepat, jogging dan istirahat. Tipe jenis gerakan ini sangat memberikan efek yang baik bagi pertambahan jumlah volum udara pada paruparu.

Metode latihan interval di atas, diharapkan mampu meningkatkan daya tahan jantung paru melalui maksimalisasi $\mathrm{VO}_{2} \max$ yang dimiliki oleh siswa ekstrakurikuler bola voli SMA Negeri 1 Gelumbang, mengingat dalam beberapa pertandingan yang peneliti amati, saat menghadapi rally-rally panjang, set-set yang justru sangat menentukan, pemain kehilangan gairah dalam bermain, kehilangan keterampilan teknik ketika bermain, lebih banyak diam padahal semestinya bola dapat dikejar, hal tersebut faktor utamanya adalah kelelahan atau tidak maksimalnya paru dan jantung dalam bekerja saat situasi pertandingan sedang berlangsung lama. Berdasarkan latar belakang inilah kemudian peneliti, tertarik untuk melakukan studi eksperimen dalam rangka meningkatkan daya tahan jantung paru pada siswa esktrakurikuler bola voli SMA Negeri 1 Gelumbang melalui latihan interval jarak pendek.

\section{METODE PENELITIAN}


Penelitian ini merupakan penelitian dengan variabel bebas yaitu latihan interval jarak pendek dan variabel terikat adalah daya tahan jantung paru. Penelitian dilaksanakan pada 22 Oktober s.d 20 November 2020. Metode yang digunakan adalah metode eksperimen dengan jenis one group pretest-postest desain. Perlakukan atau treatmen diberikan dengan frekuensi 36 jam latihan yang terbagi dalam 3-4 kali perminggu untuk satuan durasi kerja. Populasi penelitian berjumlah 24 orang siswa ekstrakurikuler bola voli. Instrumen penelitian menggunakan tes bleep/multistage fitness. Analisis data menggunakan uji $t$ dengan SPSS 16.

\section{HASIL PENELITIAN DAN PEMBAHASAN}

\section{Hasil Penelitian}

Penelitian ini memiliki tujuan untuk mengetahui ada pengaruh latihan interval jarak pendek terhadap daya tahan jantung paru pada siswa SMA Negeri 1 Gelumbang. Pelaksanaan penelitian dilakukan pada tanggal 22 Oktober s.d 20 November 2020 dengan mengedepankan protokol kesehatan, mengingat penelitian berada dalam massa pandemi covid-19. Hasil yang diperoleh dari pelaksanaan penelitian ini berupa data tes awal, data tes akhir, dan analisis data yang dijabarkan dengan langkah-langkah sebagai berikut:

1. Frekuensi Data Awal Siswa

Data awal adalah data yang didapat dari hasil tes awal siswa yaitu sebanyak 24 orang siswa esktrakurikuler bola voli SMA Negeri 1 Gelumbang yang melakukan tes bleep/multistage. Pada tabel di bawah ini dapat dilihat hasil data awal VO2max siswa esktrakurikuler bola voli SMA Negeri 1 Gelumbang:

Tabel 1. Frekuensi Data Awal Siswa

\begin{tabular}{ccc}
\hline Kategori & Frekuensi & Persentase \\
\hline Sangat Baik & 0 & 0 \\
Baik & 0 & 0 \\
Sedang & 9 & 37,5 \\
Buruk & 15 & 62,5 \\
Sangat Buruk & 0 & 0 \\
\hline
\end{tabular}


Untuk lebih jelasnya tabel di atas selanjutnya akan dipaparkan melalui diagram dibawah ini:

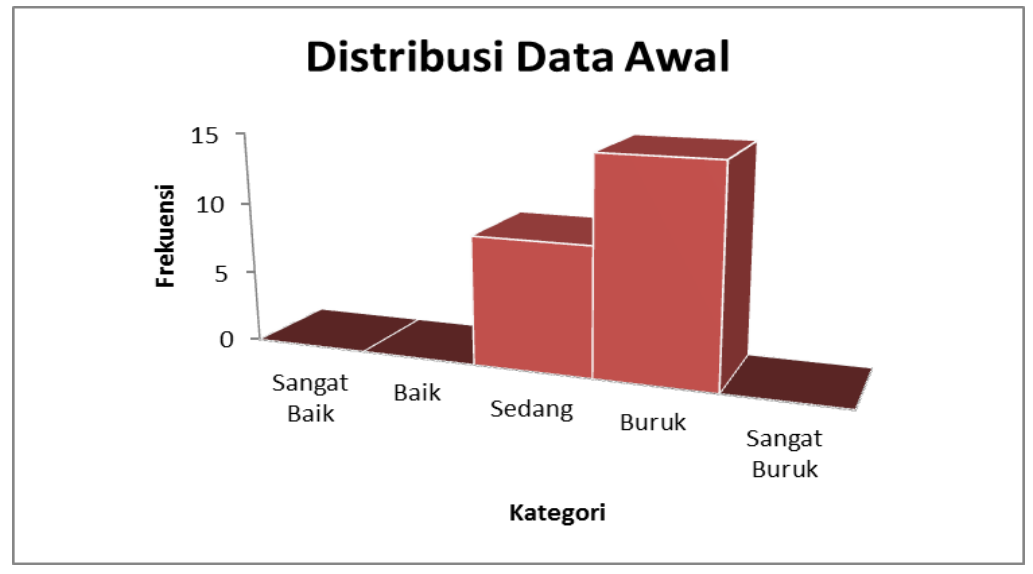

Gambar 1. Dsitribusi Data Awal

Berdasarkan tabel dan diagram di atas, dapat diperoleh informasi bahwa tidak ada siswa yang memiliki daya tahan jantung paru dengan VO2max sangat baik, tidak ada siswa yang memiliki daya tahan jantung paru dengan VO2max baik, sebanyak 9 orang atau 37,5\% siswa memiliki VO2max sedang, sebanyak 15 orang atau $62,5 \%$ siswa memiliki VO2max buruk, dan tidak ada siswa yang memiliki daya tahan jantung paru dengan VO2max sangat buruk.

\section{Frekuensi Data Akhir Siswa}

Data akhir adalah data yang didapat dari hasil tes akhir siswa yaitu sebanyak 24 orang siswa esktrakurikuler bola voli SMA Negeri 1 Gelumbang yang melakukan tes bleep/multistage. Pada tabel di bawah ini dapat dilihat hasil data awal VO2max siswa esktrakurikuler bola voli SMA Negeri 1 Gelumbang:

Tabel 2. Distribusi Data Akhir

\begin{tabular}{ccc}
\hline Kategori & Frekuensi & Persentase \\
\hline Sangat Baik & 0 & 0 \\
Baik & 0 & 0 \\
Sedang & 10 & 42 \\
Buruk & 14 & 58 \\
Sangat Buruk & 0 & 0 \\
\hline
\end{tabular}


Untuk lebih jelasnya tabel di atas selanjutnya akan dipaparkan melalui diagram dibawah ini:

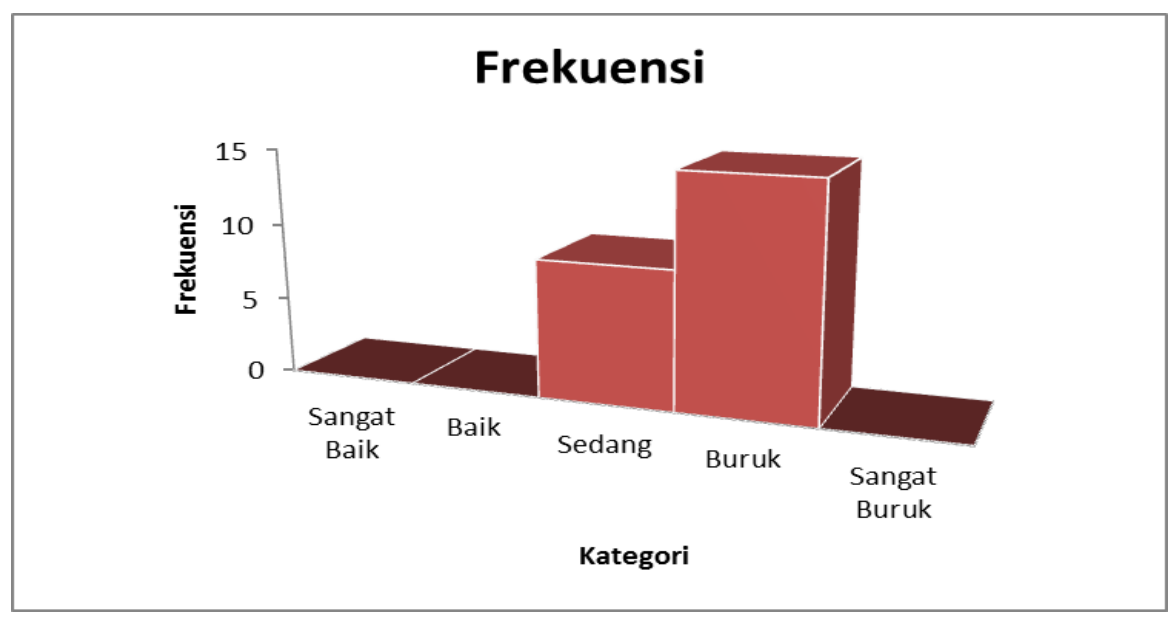

Gambar 2. Dsitribusi Data Akhir

Berdasarkan tabel dan diagram di atas, dapat diperoleh informasi bahwa tidak ada siswa yang memiliki daya tahan jantung paru dengan VO2max sangat baik, tidak ada siswa yang memiliki daya tahan jantung paru dengan VO2max baik, sebanyak 10 orang atau 42\% siswa memiliki VO2max sedang, sebanyak 14 orang atau 58\% siswa memiliki VO2max buruk, dan tidak ada siswa yang memiliki daya tahan jantung paru dengan VO2max sangat buruk.

3. Analisis Data Penelitian

a. Uji Normalitas

Pengujian normalitas dalam penelitian ini menggunakan uji kolmogrov smirnov dengan SPSS 16. Adapun pengambilan keputusan data dikatakan berdistribusi normal jika Nilai Asymp Sig Kolmogrov Smirnov besar dari 0,05. Pada tabel di bawah ini dapat dilihat hasil pengujian normalitas data:

\begin{tabular}{|c|c|c|}
\hline Statistik & Pretest & Postest \\
\hline Asymp Sig & 0,313 & 0,523 \\
\hline
\end{tabular}

Berdasarkan tabel di atas, diperoleh informasi bahwa hasil uji normalitas dengan menggunakan uji kolmogrov smirnov dapat dinyatakan data pretest 
dan data postest berdistribusi normal, mengingat hasil Asymp Sig Kolmogrov Smirnov besar dari 0,05.

b. Uji Hipotesis

Pengujian hipotesis dilakukan dalam rangka menjawab hipotesis penelitian dimana hipotesis yang diajukan adalah ada pengaruh latihan itenrval pendek terhadap daya tahan jantung paru siswa. Adapun hasil pengujian hipotesis penelitian dapat dilihat pada tabel di bawah ini:

Tabel 4. Hasil Uji Hipotesis

\begin{tabular}{ccccc}
\hline Statistik & $\mathrm{t}_{\text {hit }}$ & $\mathrm{t}_{\text {tab }}(0,05)(24-1=23)$ & $\mathrm{t}_{\text {sig }}$ & Keterangan \\
Pretest-Postest Syg & 3.281 & 1.714 & 0,05 & Signifikan \\
\hline
\end{tabular}

Berdasarkan tabel di atas penelitian ini dapat dinyatakan bahwa ada pengaruh latihan itenrval pendek terhadap daya tahan jantung paru siswa ekstrakurikuler bola voli SMA Negeri 1 Gelumbang karena thitung lebih besar dari ttabel $(3,281>1,714)$.

\section{Pembahasan}

Berdasarkan temuan hasil penelitian dan analisis data yang telah diuraikan di atas, penelitian ini dinyatakan bahwa bahwa:

a. Ada pengaruh latihan itenrval pendek terhadap daya tahan jantung paru siswa ekstrakurikuler bola voli SMA Negeri 1 Gelumbang karena thitung lebih besar dari ttabel $(3,281>1,714)$.

b. VO2max rata-rata tes awal siswa adalah $37,5 \%$ dengan kategori sedang $62,5 \%$ dengan kategori buruk,

c. VO2max rata-rata tes akhir siswa adalah $42 \%$ dengan kategori sedang dan $58 \%$ dengan kategori buruk.

Jika dilihat dari rata-rata antara data awal dan data akhir terdapat deviasi atau perbedaan jumah voleme oksigen siswa sebesar 0,95 volume. Artinya telah terjadi peningkatan jumlah volume oksigen maksimal siswa sebesar 0,95 volum akibat dari penerapan latihan interval jarak pendek yang dilakukan peneliti dan pelatih pada siswa ekstrakurikuler bola voli SMA Negeri 1 Gelumbang. 
Melihat dari besaran jumlah peningkatan tersebut, hal ini sangatlah wajar mengingat peneliti dan pelatih secara serius memberikan menu latihan sesuai dengan panduan program latihan yang telah disusun sebelumnya. Tidak satu materi latihan-pun yang tertinggal, semua telah mengikuti prosedur yang telah disusun sebelumnya bersama-sama pelatih esktrakurikuler, meskipun penelitian ini berlangsung selama massa pendami covid-19 sedang melanda termasuk daerah Gelumbang.

Pada bagian sebelumnya telah dijelaskan bahwa metode latihan interval adalah latihan yang berguna dalam meningkatkan kebugaran jasmani siswa, khususnya kebugaran fisik yang ditandai dengan meningkatnya volume oksigen maksimal. Senada dengan pendapat peneliti, dikatakan (Vidiari J, Adiatmika, Adiputra, Tirtayasa, Muliarta, \& Griadhi, 2017) bahwa salah satu bentuk latihan yang dapat meningkatkan ambang anaerobik adalah high intensity interval training. Penjelasan di atas sejalan dengan hipotesis peneliti yang kemudian dibuktikan dengan temuan hasil penelitian.

Beberapa penelitian yang sejalan dengan hasil penelitian peneliti, adalah dilakukan oleh (Ahmad, Akbar, Nur, \& Riswanto, 2020) menunukan bahwa hasil penelitian ini ada pengaruh interval training terhadap peningkatan Vo2Max renang gaya kupukupu pada atlet renang kota palopo dengan nilai yang di peroleh t-hitung sebesar 24,364>t-tabel 2,145. Penelitian lainya dilakukan oleh (Dwisetyo, Hartati, Giartama, \& Aryanti, 2019) Penelitian ini juga memberikan kesimpulan bahwa interval training yang dilakukan secara sistemasitis akan dapat meningkatkan volume oksigen maksimal (VO2Max) pada pemain futsal di SMA Negeri 6 Palembang. Penelitian lainnya dilakukan oleh ( Verena Menz, Natalie Marterer, Sachin B. Amin, Martin Faulhaber, Alexander B. Hansen and Justin S.Lawley, 2019) penelitian ini meberikan kesimpulan bahwa "High Interval Training both improve $\mathrm{VO}_{2} \mathrm{Max}$ and effect muscular endurence to the same extent despite a lower cardiovascular strain in the functional protocol" yang berarti latihan interval intensitas tinggi dapat meningkatkan kemampuan $\mathrm{VO}_{2} \mathrm{Max}$ seorang atlet. 


\section{KESIMPULAN}

Berdasarkan temuan dan analisis data penelitian, maka kesimpulan penelitian ini adalah ada pengaruh latihan interval jarak pendek terhadap daya tahan jantung paru siswa ekstrakurikuler bola voli SMA Negeri 1 Gelumbang, hal ini terbukti dengan adanya perubahan pada data $\mathrm{VO}_{2} \mathrm{Max}$ pada saat pretest dan postest yang terlihat bahwa pada saat pretest presentase siswa yang memiliki tingkat $\mathrm{VO}_{2} \mathrm{Max}$ sedang adalah $37,5 \%$ dan siswa yang memiliki tingkat $\mathrm{VO} 2 \mathrm{max}$ dengan kategori buruk adalah $62,5 \%$, data tersebut terjadi peningkatan pada saat postest setelah siswa diberikan perlakuan latihan interval jarak pendek yang menyebabkan terjadinya peningkatan kemampuan $\mathrm{VO}_{2} \mathrm{Max}$ siswa menjadi $42 \%$ dengan kategori sedang dan 58\% dengan kategori buruk, hal ini jelas membuktikan bahwa latihan interval jarak pendek dapat meningkatkan kemampuan $\mathrm{VO}_{2} \mathrm{Max}$ siswa.

Interval training jarak pendek adalah salah satu jenis latihan anaerobik yang dapat manfaatkan siswa dan pelatih untuk meningkatkan daya tahan jantung paru atau volume oksigen maksimal siswa. Semakin giat pelatih dalam memberikan menu latihan interval maka akan semakin berpengaruh pada peningkatan volume udara siswa yang terkandung dalam jantung paru siswa.

\section{REFRENSI}

Achmad, I. Z. (2016). Hubungan Antara Power Otot Tungkai, Koordinasi MataTangan, dan Rasa Percaya Diri dengan Hasil Keterampilan Open Spike Bola Voli. Jurnal Pendidikan Unsika, Volume 4 Nomor 1.

Ahmad, Akbar, A. K., Nur, S., dan Riswanto, H. A. (2020). Pengaruh Interval Training Terhadap Peningkatan VO2max Renang Gaya Kupu-Kupu Atlet Renang Kota Palopo. Jurnal Pendidikan Glasser, Volume 4 Nomor 1.

Akhbar, M. T. (2020). Pengaruh Latihan Curl Dumble Terhadap Hasil Smash Bola Voli. Halaman Olahraga Nusantara, Volume 3 Nomor 1. DOI: "http://dx.doi.org/10.31851/hon.v3i1.3702"

Barbara. (2004). Bola Voli. Jakarta: PT. Rajagrafindo Persada. 
Dwisetyo, M. R., Hartati, Giartama, dan Aryanti, S. (2019). Pengaruh Interval Training Terhadap Volume Oksigen Maksimal pada Ekstrakurikuler Futsal. Journal of Sprot Science and Education (JOSSAE), Volume 4 Nomor 1.

Fitria, Jafar, M., dan Karimudin. (2015). Evaluasi Daya Tahan Jantung Paru Anggota Mapolda Aceh. Jurnal Ilmiah Mahasiswa Penjaskes Unsyiah , Volume 1 Nomor 3.

Hardiansyah, S. (2017). Pengaruh Metode Interval Training Terhadap Peningkatan Kesegaran Jasmani Mahasiswa Pendidikan Olahraga. Jurnal Penjakora, Volume 4 Nomor 1.

Heri, J., Supriatna, E., dan Purnomo, E. (2015). Survei Keterampilan Teknik Dasar Bola Voli . Jurnal Prodi Penjaskesrek.

Hidayat, S. (2014). Pelatihan Olahraga. Yogyakarta: Graha Ilmu.

Ihsan, Nur, Mentara, H., dan Kamarudin. (2017). Pengaruh Latihan Intreval Terhadap Kecepatan Permainan Futsal pada Atlet Orinity. Tadulako Journal Sprot Sciences and Physical Education, Volume VI Nomor 1.

Junusul, H. (2010). Dasar-Dasar Kesehatan Olahraga. Jakarta: Universitas Terbuka.

Kurnia, Maya., Anggraini, Hamida. (2020). Pengaruh Latihan Jogging Terhadap Daya Tahan Kardiorespirasi Pada Atlet Taekwondo Survivar 5 Club Palembang. Halaman Olahraga Nusantara, Volume 3, Nomor 1. DOI: http://dx.doi.org/10.31851/hon.v3i1.3558

Menz, Verena., Marterer, Natalie., B. Amin, Sachin., Faulhaber, Martin., B. Hansen, Alexander and S.Lawley, Justin. (2019). Functional Vs. Running Low-Volume High-Intensity Interval Training: Effects on $\mathrm{VO}_{2} \mathrm{Max}$ and Muscular endurance. Journal of Sport Science and Medicine, Dept. of Sport Medicine, Medical Faculty of Uludag University.

Ricky, Z. (2020). Pengaruh Latihan Box Drill Terhadap Kemampuan Smash Bola Voli. Halaman Olahraga Nusantara, Volume 3, Nomor 2. DOI: http://dx.doi.org/10.31851/hon.v3i1.3702

Saleh, Y. A., dan Nurhayati, F. (2014). Perbandingan Kemampuan Daya Tahan Jantung Paru dan Paru-Paru Antara Siswa Kelas XI pada Pembelajaran Penjas Saat Siang dan Sore Hari. Jurnal Pendidikan Olahraga dan Kesehatan, Volume 2 Nomor 1. 
Suharsimi, A. (2006). Metode Penelitian. Jakarta: Alfabeta.

Sukadiyanto. (2011). Melatih Fisik. Jakarta: PT Rajagrafindo Persada.

Sukirno. (2012). Kesegaran Jasmani, Doping dan Kesehatan Olahraga. Palembang: Unsri Pers.

Sukma, A. (2015). Buku Olahraga Paling Lengkap. Pamulang: Ilmu-Bambu APus.

Sungkowo, Rahayu, K., dan Budianto, S. K. (2015). Pengaruh Latihan Interval dan Kapasitas Vital Paru Terhadap Kecepatan Renang 50 Meter. Jurnal Media Ilmu Keolahragaan Indonesia, Volume 5 Nomo 1.

Vidiari J, I., Adiatmika, I. P., Adiputra, L., Tirtayasa, K., Muliarta, M., dan Griadhi, A. (2017). High Intensity Interval Training (HIT) Lebih Meningkatkan Ambang Anaerobik Daripada Steady State Training pada Siswa. Sport Fitness Journal, Volume 5 Nomor 3. 